\title{
CDISC SEND Fetal Pathology Findings Result Category Terminology
}

National Cancer Institute

\section{Source}

National Cancer Institute. CDISC SEND Fetal Pathology Findings Result Category

Terminology. NCI Thesaurus. Code C124313.

Terminology associated with the fetal pathology findings result category codelist of the Clinical Data Interchange Standards Consortium (CDISC) Standard for the Exchange of Non-clinical data (SEND). 